\title{
Utilization of hospital services during delivery among post-natal mothers in Thika urban and Kangundo rural Counties, Kenya
}

Kabue $\mathrm{P}^{1}$, Keraka $\mathrm{M}^{2}$, Simbauni $\mathrm{J}^{3}$

\section{${ }^{I}$ Kenyatta University School of Nursing, Department of Community Health Nursing, Nairobi, \\ Kenya \\ ${ }^{2}$ Kenyatta University, Department of \\ Reproductive and \\ Population, Nairobi, \\ Kenya \\ ${ }^{3}$ Kenyatta University Department of Zoological Sciences, Nairobi, Kenya}

Corresponding author: Dr Priscilla Kabue, Kenyatta University, School of Nursing, Department of Community Health Nursing. PO Box 43844-00100 Nairobi, Kenya. Email: Kabue. priscilla@ku.ac.ke

\section{Abstract}

Background: Maternal mortality rate due to pregnancy-related complications in Kenya remains high at 362 per 100,000 live births. Hospital deliveries are low despite government strategies on improving health system and human resources. Home delivery practice is common in many parts of Kenya, especially in the rural areas. Generally, midwifery in home delivery lacks the necessary expertise to identify, resolve or prevent maternal complication, a situation which could raise maternal delivery related morbidity and mortality rates.

Objectives: The study aimed to determine the rates of hospital deliveries both in urban and the rural hospital settings and establish the factors that determined the choice for hospital services.

Methods: The study population was composed of post-natal mothers attending Maternal Child Health Clinics in an urban hospital setting and a rural hospital setting. The mothers were those who had delivered less than one year earlier. Thika Level 5 Hospital in Kiambu County represented the urban setting while Kangundo Level 4 Hospital represented the rural setting. A total of 400 post-natal mothers in each of the two hospitals were interviewed using a structured questionnaire to collect the relevant data in each hospital. Focus Group Discussions and Key informants interviews were also conducted in each hospital.

Results: Client specific factors that were associated with hospital delivery included a steady source of income and occupation $(\mathrm{p}=0.028, \mathrm{p}=0.007)$, ability to pay for hospital expenses and remedies $(\mathrm{p}=0.000, \quad \mathrm{p}=0.00)$, accessibility and short distance from the health facility ( $\mathrm{p}$ $=0.001, p=0.029)$, and client having a positive experience from a previous delivery and hope for a better services in the hospital $(\mathrm{p}=0.000, \mathrm{p}=0.000)$ respectively. Health facility factors were lack of privacy $(\mathrm{p}=0.000)$ manner in which the mother was handled by the health care worker $(p=0.0901)$ and the expected care $(\mathrm{p}=0.017)$.

Conclusion: The study concludes that mothers fail to utilize the health facility for delivery due to service related factors such as long distance from the hospital, negative attitude of health workers, lack of privacy and poor quality of care, an improvement of which will make them deliver in hospitals and not at home.

\section{Introduction}

Background information: Complications associated with pregnancy and childbirth is the leading cause of death and disability among women of reproductive age in developing countries, Kenya included. Globally, maternal mortality stands at 216 maternal deaths per 100,000 live births. Sub-Saharan Africa has the highest Maternal Mortality Rate (MMR) at 546 maternal deaths [1]. Of the estimated 303,000 maternal deaths worldwide in 2015, developing countries accounted for more than $99 \%$ deaths in which $66 \%$ occurred in sub-Saharan Africa alone compared to only 12 in the developed world [1]. Global targets for ending preventable maternal mortality by 2030 , states that every country should reduce its Maternal Mortality Rate (MMR) by at least two thirds from the 2010 baseline, and no country should have an MMR higher than 140 deaths per 100,000 live births twice the global target [1].

Maternal mortality in Kenya stands at 362 per 100,000 live births [2]. Nearly a third of a million women die each year because of complications related to pregnancy and childbirth. Haemorrhage is the leading cause of death. Sepsis, prolonged or obstructed labour, hypertensive disorders of pregnancy, especially eclampsia, and complications of unsafe abortion, also play an important role as cause of maternal delivery related morbidity 
and mortality [3]. The complications could be prevented in many cases if the mothers were all attended to by skilled health workers in health facilities during labour. However, only $62 \%$ of births in Kenya are attended by a skilled attendant and $61 \%$ utilize health facilities [2] despite introduction of free maternity services in Kenya in June 2013 [4].

Traditional Birth Attendants (TBAs) play a vital role in home labour deliveries despite the government policy that, TBAs are not recognized as skilled attendants and should refer mothers to the hospital. For example, in Machakos County, Traditional Birth Attendants (TBAs) attended to over 200 pregnant women over a period of 5 years by 2014 [5].

Despite the decrease of MMR from 488 in 2009 to 362 in 2014 Kenya was categorized as having made insufficient progress by the Millennium Developed Goals 1990 to 2015 which aimed at reducing MMR by $75 \%$. The Sustainable Development Goals aims to achieve global MMR of 70 maternal deaths by 2030. Therefore, it cannot be overemphasized that TBAs contributes to the increase in MMR in the country especially in the rural areas where their services becomes handy in times of economic difficulties. Reducing maternal mortality requires a sustained, long-term commitment and the involvement of a range of partners. Hospital deliveries lead to a reduction in maternal morbidity and mortality.

Objectives: The study aimed to determine the rates of hospital deliveries both in urban and the rural hospital settings and establish the factors that determined the choice for hospital services.

\section{Materials and Methods}

This was a cross sectional quantitative and descriptive survey. Thika Level 5 Hospital was the urban setting and Kangundo County Hospital the rural setting. The study population included all postnatal mothers attending $\mathrm{MCHC}$ in each hospital who had delivered less than one year earlier, irrespective of the place of delivery. A total of 400 mothers were interviewed from each hospital.
Data was analyzed using SPSS version 16 for windows. Descriptive and inferential statistics were used in the study.

\section{Results}

Obstetric history of a total of 800 women from both urban and rural hospitals indicated that an overall $79.6 \%$ of the women delivered in the hospital and $20.6 \%$ delivered at home. Considering the two regions 281 (70.2\%) of the mothers in Kangundo delivered in the hospital and $29.8 \%$ delivered at home while in Thika this was $88.5 \%$ and $11.5 \%$ respectively (Table 1 ).

Table 1: Pattern of obstetric hospital or home deliveries both in urban and rural hospitals

\begin{tabular}{lccc}
\hline Place of delivery & \multicolumn{3}{c}{ Hospital } \\
\cline { 2 - 4 } & Kangundo & Thika & Total \\
\hline & $(\mathrm{n}=400)$ & $(\mathrm{n}=400)$ & $(\mathrm{N}=800)$ \\
& $(\%)$ & $\%$ & $(\%)$ \\
Hospital & $281(70.2)$ & $354(88.5)$ & $635(79.4)$ \\
\hline Home & $119(29.8)$ & $46(11.5)$ & $165(22.6)$ \\
\hline
\end{tabular}

Considering levels of education, a higher proportion of those with low levels of formal education in the rural area delivered at home compared to those in the urban area (Table 2). Data on occupation in Kangundo Hospital indicated that utilization of hospital services was lowest in housewives $(67 \%)$ and those with no specific job $(66.3 \%)$ but increased with self-employment $(81.8 \%)$ and formal employment $(88.9 \%)$. However, proportion of hospital deliveries in Thika was (89.9\%) for housewives and $(92 \%)$ for self-employed respectively.

Results of factors related to the size of the house indicated that the proportion of hospital utilization was higher in the urban dwellers than in those dwelling in the rural houses. Those living in self-contained houses had the highest frequency of hospital deliveries $(98.3 \%$ in Thika and 91.7\% in Kangundo respectively (Table 2). 
Table 2: Client socio-demographic factors influencing place of delivery in Thika and Kangundo hospitals

\begin{tabular}{|c|c|c|c|c|c|c|c|c|c|c|}
\hline \multirow[b]{4}{*}{ Education level } & \multicolumn{10}{|c|}{ Place of delivery } \\
\hline & \multicolumn{4}{|c|}{ Thika } & & \multicolumn{5}{|c|}{ Kangundo } \\
\hline & \multicolumn{4}{|c|}{ Hospital Home } & \multirow[b]{2}{*}{$p$} & \multicolumn{3}{|c|}{ Hospital Home } & \multirow[b]{2}{*}{$(\%)$} & \multirow[b]{2}{*}{$p$} \\
\hline & (n) & $(\%)$ & (n) & & & (n) & $(\%)$ & (n) & & \\
\hline Primary & 145 & 85.3 & 25 & 14.7 & 0.45 & 129 & 61.4 & 81 & 38.6 & 0.00 \\
\hline Secondary & 168 & 88.9 & 21 & 11.1 & & 125 & 79.1 & 33 & 20.9 & \\
\hline Tertiary & 40 & 97.6 & 1 & 2.4 & & 27 & 84.4 & 5 & 15.6 & \\
\hline \multicolumn{11}{|l|}{ Occupation of mother } \\
\hline Housewife & 222 & 89.9 & 25 & 10.1 & 0.007 & 146 & 67 & 72 & 33 & 0.028 \\
\hline Employed & 81 & 92 & 7 & 8.0 & & 54 & 81.8 & 12 & 18.2 & \\
\hline Formal employment & 50 & 76.9 & 15 & 23.1 & & 16 & 88.9 & 2 & 11.1 & \\
\hline Others & - & - & - & - & & 65 & 66.3 & 33 & 3.7 & \\
\hline Size of house & & & & & & & & & & 0.62 \\
\hline One room & 189 & 86.3 & 30 & 13.7 & .002 & 37 & 80.4 & 9 & 19.6 & \\
\hline Two rooms & 104 & 95.4 & 5.0 & 4.6 & & 80 & 65 & 43 & 35 & \\
\hline Self-contained & 26 & 96.3 & 1.0 & 27 & & 11 & 91.7 & 1 & 8.3 & \\
\hline Others & 34 & 75.6 & 11 & 24.4 & & 153 & 69.9 & 66 & 30.1 & \\
\hline \multicolumn{11}{|c|}{ Gestation 1st clinic (weeks) } \\
\hline$<16$ & 65 & 84.4 & 12 & 15.6 & 0.36 & 54 & 79.4 & 14 & 20.6 & 0.14 \\
\hline $16-24$ & 139 & 89.7 & 16 & 10.3 & 174 & 72.2 & 67 & 27.8 & & \\
\hline $28-32$ & 131 & 91.6 & 12 & .4 & & 43 & 62.3 & 26 & 37.7 & \\
\hline$>36$ & 16 & 84.2 & 3.0 & 15.8 & & 7.0 & 43.8 & 9.0 & 50.3 & \\
\hline \multicolumn{11}{|l|}{ Clinic attendance } \\
\hline None/once & 15 & 71.4 & 6.0 & 28.6 & & 6.0 & 31.6 & 13 & 68.4 & 0.00 \\
\hline Twice & 52 & 96.3 & 2.0 & 3.7 & & 25 & 61.1 & 16 & 39.1 & \\
\hline Thrice & 81 & 88 & 11 & 12 & 0.026 & 89 & 64.5 & 38 & 35.5 & \\
\hline Four and above & 208 & 88.4 & 27 & 11.6 & 181 & 77.7 & 52 & 23.3 & & \\
\hline
\end{tabular}

For the factors related to health facilities and the mothers views on the attitude of the healthcare givers only $17 \%$ of the mothers in Kangundo and $22.5 \%$ in Thika reported that they were handled in a friendly manner while $5.1 \%$ and $34.2 \%$ in Kangundo and Thika reported that they were handled harshly, respectively (Figure 1) but there was no significant difference. 


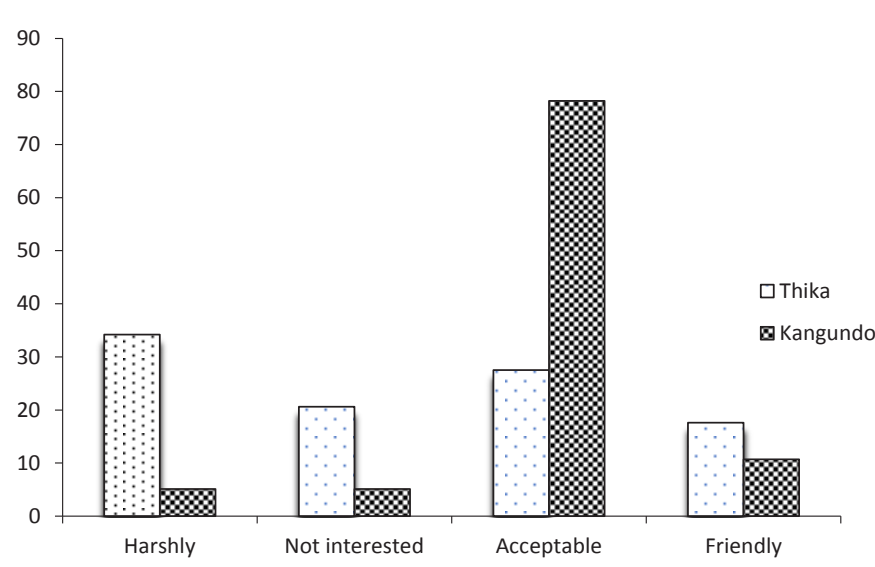

Figure 1: Views of the mothers on the attitude of healthcare givers during hospital deliveries services

The attitude of health workers during hospital deliveries and the condition of the hospital were assessed by the mothers (Table 3 ). The way the health worker was viewed by the mothers was statistically significant in Kangundo Hospital only. A hospital being seen as a comfortable place to deliver was significant in Kangundo only $\chi^{2}=96.8, \mathrm{df}=1: \mathrm{p}=0.000$. In Kangundo utilization of hospital delivery was associated with the feeling of the mother whether hospital was a comfortable place for delivery or not.

Mothers were asked about the attitude of health workers during hospital deliveries, if it was comfortable to deliver in hospital, the distance to the hospital from their homes, the question of transport money to hospital for delivery and if previous delivery in hospital influenced later choices (Figure 2).

Having money to go to the hospital and pay for services was statistically associated with hospital delivery in Kangundo $(\mathrm{P}=0.001)$. Utilization of hospital for delivery was associated with whether the mother had money to pay for the services or not in both hospitals. Distance from the health facility was found to be statistically significant in Kangundo $\chi^{2}=15.9, \mathrm{df}=3: \mathrm{p}=0.001$ and Thika $\chi^{2}=$ 9.0, $\mathrm{df}=3: \mathrm{p}=0.029$. Utilizing the hospital for delivery services in Kangundo was associated with the distance from the mothers' home to the hospital.

Previous hospital delivery was statistically significant with present hospital delivery. Utilizing the hospital for delivery was associated with the mother having delivered in a hospital earlier in both Thika and Kangundo Hospitals respectively $\chi^{2}=238.3, \mathrm{df}=1: \mathrm{p}=0.000$ District hospital $\chi^{2}=13.3, \mathrm{df}=1: \mathrm{p}=0.000$ (Table 3$)$.

Table 3: Client oriented factors on healthy facility that determine hospital delivery

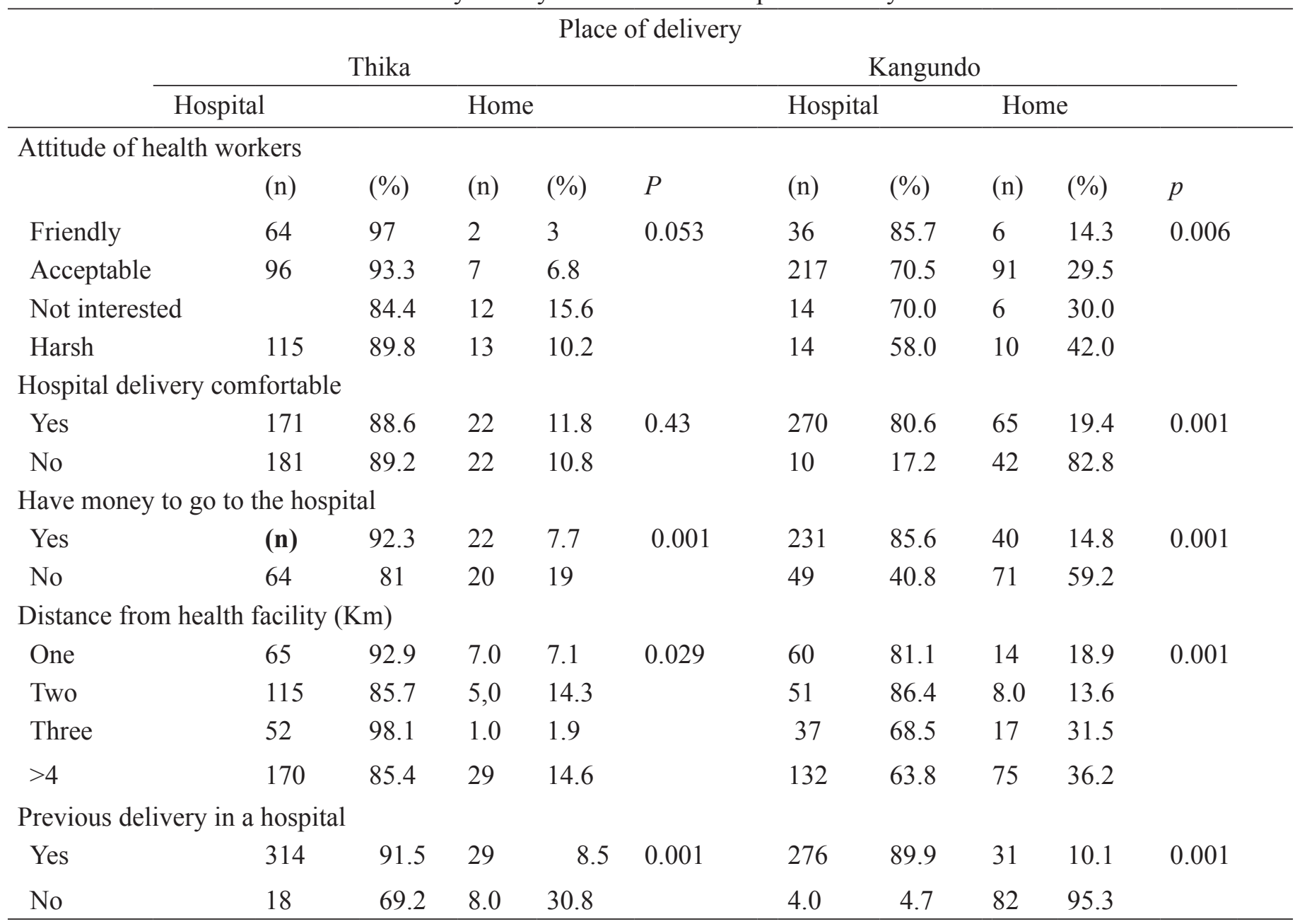


In terms of cleanliness of the hospital (floor, bed sheets and instruments used) and the state of the health workers $98.6 \%$ of the mothers in Kangundo reported the hospital to be clean compared to only $35.1 \%$ in Thika. Concerning the workers, $30.9 \%$ in Kangundo and $56.4 \%$ in Thika reported that the health workers looked overworked and tensed (Figure 2).

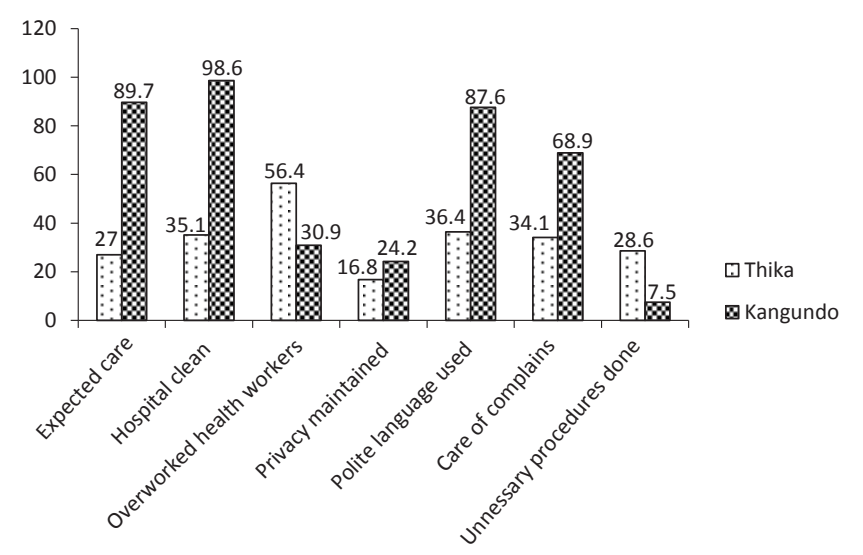

Figure 2: Client assessment of health care services during delivery

Figure 3 details the areas in which the mothers felt they should be improved or rectified to make the choice of hospital delivery more favourable. Majority of the respondents from both Kangundo and Thika recommended increased number of workers 71 (26.2\%) and $94(27 \%)$ respectively. Taking health facility closer to the community was also important.

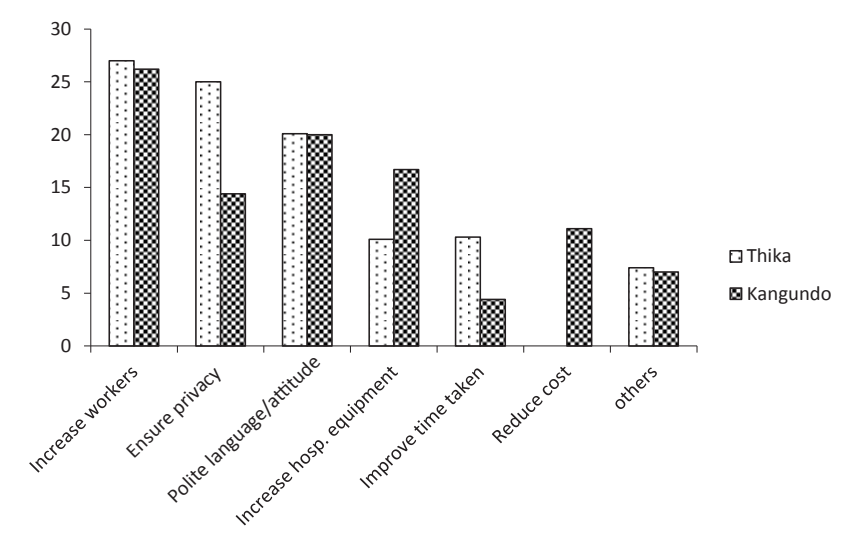

Figure 3: Mothers view on the areas which required improvement in order to attract more hospital deliveries.

\section{Discussion}

Majority $(79.6 \%)$ of the mothers in the study reported to have delivered in the hospital a figure that is higher than the national average in Kenya where only $61 \%$ births took place in hospital [2]. Considering the two regions a higher percentage of mothers in the urban area delivered in the hospital compared to the mothers in the rural area but there was no significant difference $(\mathrm{P}=0.000)$.

Majority of the women attending the post natal clinic reported to have delivered in the hospital but significantly low number of women delivered in Kangundo Hospital than in Thika Hospital $(\mathrm{P}=0.000)$. Considering that the study was conducted in the hospital setting those who had delivered in the same hospital were likely to come back for postnatal check-up and immunization a factor that could explain the contrast with the Kenya Demographic and Health Survey (KDHS 2014 data where only $61 \%$ of women delivered in health facilities [2]. Hospital deliveries were significantly higher in Thika $(86.5 \%)$ than $(70.2 \%)$ in Kangundo $(\mathrm{P}<0.001)$. The higher number of home deliveries in Kangundo (29.8\%) could be associated with low rural socioeconomic status, long distance from home to hospital and the fact that TBAs were readily available whereas more mothers could access hospital services in Thika, an economically advantaged and better educated, urban area.

Similar observations were reported in Burkina Faso in which $72 \%$ of women delivered in the hospital [7] but the rates were slightly higher than the ones recorded in Kangundo and lower than the ones in Thika. This could be attributed to the fact that Burkina Faso study was conducted in an urban area and that services were free in that country unlike the rural Kangundo where services were not free in Kenya (at the time of study). Again, the number of women who delivered in Kangundo Hospital was proportionally higher than the $43.5 \%$ national figure for hospital delivery in Nigeria [6] at the time of our study and higher than $68.5 \%$ in a teaching hospital also in Nigeria [8].

Level of education was statistically associated with utilization of hospital delivery in Kangundo but there was no significance difference $(\mathrm{P}<0.001)$ in Thika where majority of the respondents utilized hospital services during delivery irrespective of level of education. Similar observation was recorded in a Nigerian study [8] in which level of education was bound to influence utilization of maternal health care during delivery a finding also reported by Kenya Demographic and Health Survey (KDHS 2014 [2, 6, 10] and in Tanzania where level of education positively influenced the place of delivery $[11,12]$.

Occupation of the mothers also played a role in determining the choice of hospital services in the rural area but it was not significant in the urban hospital $(\mathrm{P}<0.028)$. This could be attributed to the fact that there are many educated people in town who are likely to influence hospital delivery even among housewives, and friends as well as the fact that spouses could be more economically stable compared to their rural counterparts. Besides, the fact that TBAs are not readily available in the urban area leaves the mothers with no alternative but to seek hospital services. 
Size of the house in Thika was also a determining factor to hospital delivery in which the larger the number of rooms the higher the proportion of women who delivered in the hospital. Higher utilization of hospital services in the urban could be influenced by the fact that the size of the house in the urban area is a true representative of the economic status of the individual compared to rural area where majority of the people live in their homes rather than the rental houses in towns [2]. Those who lived in self-contained houses (96.3\%) were more likely to seek hospital services than those who lived in one room $(86.3 \%)$. Other studies also conducted in Kenya made similar observations $[11,13]$.

The gestation period at which mothers started visiting the antenatal clinic was significant in Kangundo Hospital $(\mathrm{P}<0.014)$. Those who started visiting the clinic before week 16 of gestation (79.4\%) were more likely to choose to deliver in the hospital compared to those who visited the clinic for the first time after week 36 of gestation (43.8\%). Our data compares favorably with the findings of Kenya Demographic and Health Survey 2008/9 [13].

Attitude of health workers towards the mothers during delivery and the mothers' views of the hospital environment were also important determinants of the choice for hospital or home delivery. In Kangundo Hospital, those who viewed the health worker as friendly $(83.7 \%)$ and acceptable (70.5\%) were more likely to utilize the hospital as compared to those who viewed them as uninterested $(30 \%)$ and harsh (42\%). In the rural area about $81 \%$ of those who felt that hospital was a comfortable place for delivery delivered in the hospital compared to about $87 \%$ in urban area.

The condition of the hospital was also an important factor for the choice of hospital services in which significantly higher proportion $(\mathrm{P}=0.000)$ of mothers in the rural hospital $(98.6 \%)$ reported the facility to be clean compared to the urban area (35.1\%). Overworked personnel could compromise on the cleanliness of a facility as $56.4 \%$ of the mothers in Thika reported the workers to be overworked and stressed as compared to those in Kangundo, reported by only $30.9 \%(\mathrm{P}=0.001)$.

Distance from the hospital was also important in the choice for hospital services. In Thika, those who lived more than four kilometers away from the hospital (85.4\%) compared to only $63.8 \%$ in Kangundo hospital who utilized hospital services. This was also reflected in the ability to raise transport fare which was easier in the urban than in the rural setting. Our study compares favorably with Bukina Faso one where those living within 5 kilometers of the hospital were found to be utilizing the hospital more [7]. Majority of the mothers who had utilized the hospital delivery before were more likely to deliver in the hospital compared to those who were using hospital for the first time. Mothers recorded their concern over the factors which discourage them from choosing hospital delivery in favour of home delivery and they were ready for hospital delivery on improvement of such negative condition, thus a reduction of maternal mortality. There was a glaring need to increase the number health workers, to have health facilities closer to the communities and to ensure privacy of the mothers.

\section{Conclusions}

The proportion of hospital deliveries was higher in urban than in rural area, a situation that could be attributed to socioeconomic factors, level of education, distance from the public hospital, previous deliveries in the hospital, number of visits to antenatal clinics and gestation period when the mother started visiting the clinic. Negative attitude of the healthcare givers towards the mothers, poor quality of obstetric care in the previous deliveries, inadequate obstetric care facilities, and poor hospital hygiene were also important factors that lead to the choice of hospital or home deliveries.

Mothers recorded their concern on the factors which discourage them from choosing hospital delivery in favour of home delivery and they were ready for hospital delivery on improvement of such negative condition, thus a reduction of maternal mortality. Similarly, enforcement of national policy on TBAs would be essential in achieving the WHO Sustainable Development Goals that no country should have an MMR higher than 140 deaths per 100000 live births .

\section{References}

1. World Health Organization (WHO). Trends in Maternal Mortality: 1990 to 2015 Estimates by WHO, UNICEF, UNFPA, The World Bank and the United Nations Population Division. WHO 2015. http://www.who.int/reproductivehealth/ publications/monitoring/maternalmortality-

2. KDHS and ICF-Macro. Kenya Demographic and Health Survey. Calverton, Maryland: Kenya National Bureau of Statistics and ICF Macro, 2014. KDHS 2014. http://dhsprogram.com/pubs/pdf/ PR55/PR55.pdf

3. WHO, UNICEF, UNFPA and World Bank Estimates, (2012).Trends in maternal deaths 1990 to 2010 .

4. Bourbonnais N. (2013). Implementing free maternal health care in Kenya. Challenges, Strategies and Recommendations-KNHCR.

5. Kaingu CK, Achieng JO and Kanui TI. Practices of traditional birth attendants in Machakos District, Kenya. J. Ethnopharmacol. 2011; doi:10.1016/j. jep.2011.05.044

6. Babalola S and Fatusi A. Determinants of use of maternal health services in Nigeria looking beyond individual and household factors. $B M C$ Pregnancy Childbirth. 2009; (9) 43. https://doi. org/10.1186/1471-2393-9-43. 
7. De'Allegri M, Riddeb V, Louisa VR, Sarkera M, Tiendrebéogoc J, et al. Determinants of utilization of maternal care services after the reduction of user fees: A case study from rural Burkina Faso. Health Policy. 2010; doi:10.1016/j.healthpol.2010.10.010

8. Ekele BA and Tunau KA. Place of delivery among women who had antenatal care in a teaching hospital in Nigeria. Acta Obstet Gynecol Scand. 2007; 86: 627-630. PubMed Abstract

9. Van Eijk AM, Bles HM, Odhiambo F, Ayisi JG, Blokland IE, et al. Use of antenatal services and delivery care among women in rural western Kenya: a community based survey. Reprod Health. 2006; 3:2. Published online 2006 Apr 6.doi: 10.1186/1742-4755-3-2 PMCID: PMC 1459114.

10. Moindi RO, Ngari MM, Nyambati VCS and Mbakaya C. Why mothers still deliver at home: understanding factors associated with home deliveries and cultural practices in rural coastal Kenya, a cross-section study. BMC Public Health. 2016; 16: PMC4738797.
11. Fotso JC, Ezeh A, Ogollah R and Abdhallah Z. What does access to maternal care mean among the urban poor: Factors associated with use of appropriate maternal health services in the slum settlements of Nairobi, Kenya. Maternal Child Health J. 2009; 13 (1): 130-137.

12. Mpembeni RNM, Killewo JZ, Leshabari MT, Massawe SN, Jahn A, Mushi D, et al. Use pattern of maternal health services and determinants of skilled care during delivery in Southern Tanzania: implications for achievement of MDG-5 targets. BMC Pregnancy Childbirth. 2007; 7:29.

13. KDHS and ICF-Macro. Kenya Demographic and Health Survey 2008/9. Calverton, Maryland: Kenya National Bureau of Statistics and ICF Macro, 2010. http://dhsprogram.com/pubs/pdf/fr229/fr229.pdf

14. African Population and Health Research Centre (APHRC) and World Bank (2006). Averting preventable maternal mortality: Delays and barriers to the utilisation of emergency obstetric care in Nairobi's informal settlements. Nairobi, Kenya. 